\title{
Effect of the Theory of Planned Behavior Education on Nutritional Behaviors of Overweight and Obese Women Before Pregnancy
}

\author{
Ameneh Khayeri ${ }^{\circledR}$, Zohreh Mahmoodi' ${ }^{2}$ Mitra Rahimzadeh $^{3}$, Leili Salehi ${ }^{4}, Z_{\text {Zahra Behboodi Moghadam }}^{5}$, \\ Sara Esmaelzadeh Saeieh ${ }^{*}$ (D)
}

\begin{abstract}
Objectives: Maternal nutritional behavior before and during pregnancy contributes significantly to improving the outcomes of pregnancy and the health of the newborns after birth. In addition, the theory of planned behavior (TPB) is a proper model for use during pre-pregnancy and pregnancy. Therefore, the present study evaluated the effect of TPB education on nutritional behaviors of overweight and obese women before pregnancy.

Materials and Methods: This randomized controlled trial was conducted on 100 overweight and obese women who attended a nutrition unit in Khansar during April-August 2017. A convenient sampling method was used and the samples were randomly divided into intervention and control groups. The intervention group participated in five nutritional training sessions based on the TPB in addition to routine care. Data were collected with TPB and nutritional behaviors questionnaires before, after, and 2 months after education. Finally, the Student's t test, Fisher exact test, as well as Mann-Whitney U test, chi-square and repeated-measure tests were utilized for data analysis.

Results: Based on the result of the repeated measure test, the overall score of the TPB changed $(P=0.002)$ over time and a significant difference was observed between the 2 groups $(P=0.002)$. In addition, the result of the repeated measure test indicated that the length of time affects the nutritional behavior score $(P=0.000)$ and there was a significant difference between the 2 groups in this regard $(P=0.000)$.

Conclusions: Considering the effect of training, based on the TPB, on nutritional behavior, the content of this training is suggested to be included in the pre-pregnancy program.

Keywords: Obesity, Overweight, Before pregnancy, Theory of planned behavior
\end{abstract}

\section{Introduction}

Overweigh is a chronic disease that affects people of all ages in every region of the world (1) and overweight pregnant women are more prone to complications during pregnancy. They are at higher risk for gestational diabetes, high blood pressure, and preeclampsia. In addition, maternal obesity is associated with a higher risk of death from abortion and intrauterine death, prolonged pregnancy, and the increased risk of cesarean section. It is related to fetal risks in addition to maternal risks. Further, the infants of obese mothers are more at risk for embryonic developmental disorders, prematurity, abnormalities, and other clinical side effects (2). In the United States, 3 out of every ten women between the ages of twenty and forty years are obese or overweight (1). In every 1000 women who give birth in England, one woman is very obese as well (3). Due to changes in lifestyle and nutritional patterns, the prevalence of obesity has increased in recent decades in Iran. The scattered surveys from different parts of Iran show that obesity in women is more than twice as likely to occur in men in all age groups over fifteen years (4).

Over the past few decades, there has been a significant increase in the prevention and treatment of obesity around the world, which includes all age groups including women of reproductive age (5).

The importance of women's health before and during pregnancy has led to a growing pre-pregnancy care over the past decade. Evidence suggests that improvement in women's health behaviors can enhance the pregnancy outcome and the newborns' health after birth (6). Maternal nutritional behaviors before and during pregnancy play an important role in infant and child health (7).

Changing people's attitudes is one of the ways of altering their food habits. Theories can determine the characteristics, beliefs, and individual values that are associated with health behaviors (8).

The theory of planned behavior (TPB) by Ajzen and Fishbin contains 3 main components on behavioral intent. The attitude refers to the fact that a person has a positive or negative view of health behavior. Furthermore, the 
subjective norm is a perceived social pressure to conduct behavior that involves individual beliefs about whether the key individuals approve or reject the behavior. The perceived behavioral control is the measure of perceived control over the behavior (9). Various studies used this theory to determine the attitudes and beliefs associated with nutritional behaviors (8). It is possible to mention the consumption of fast foods, fruits, vegetables, snacks, low-fat foods, breakfast, and saturated fats (10)

The TPB is an appropriate framework for use in prepregnancy and pregnancy because the structures of this theory affect the aspects of the pregnancy. For example, women's attitudes toward physical activity may change due to their personal beliefs. Moreover, the excessive usage of calories may happen due to the advice of friends and relatives who you consider to be 2 people in pregnancy (subjective norm), a woman may have no control over her overweight. In contrast, the mother tends to limit the increase in her weight pre-pregnancy and pregnancy (perceived behavioral control) that influences her intention on food behavior (11).

There is a lack of studies on the effect of pre-pregnancy interventional programs on nutritional behaviors in overweight and obese women. Considering the effects of overweight and obesity on the outcome of pregnancy and delivery, this study was designed to investigate the effect of pre-pregnancy nutritional education program, based on the TPB, on the nutritional behavior of overweight and obese women.

\section{Materials and Methods}

The current study was a randomized controlled trial. The subjects of this study consisted of obese or overweight women and referred to the nutrition unit of Khansar Health Center based on their desire for pregnancy. This center has 150 referrals monthly, of which approximately 35 cases are obese or overweight women who intend to be pregnant. According to Bahadori-Monfared et al, the sample size was 55 in each group (12). Given the probability sample dropped out, it was decided to examine 2 groups of 65 people. In the intervention group, 7 people were excluded from the study due to the lack of participation in all education sessions and 8 participants became pregnant. In the control group, 10 people were excluded from the study due to their reluctance to participate in the study and 5 people were excluded from the study due to pregnancy (Figure 1). The study continued with 50 participants per group. The sampling lasted from April to August 2017. The inclusion criteria were being within the age range of 18 to 40 years old, having a singleton pregnancy, having a body mass index of 25 and above, having reading and writing literacy, and being fluent in the Persian language. Likewise, the exclusion criteria included having a history of weight gain hormonal diseases, weight gaining drugs, as well as physical and mental illnesses and infertility, having high-risk pregnancy indications, following a specific diet, and not attending 2 education sessions. The researcher who was an MSc midwifery student obtained the necessary permission from the faculty and university in order to refer to the center every day of the week. After explaining the objectives of the study and obtaining the oral and written consent, the study samples were randomly assigned to 2 groups by table numbers in order to receive an education (intervention) and routine care (control).

The overall score of the theory of the planned behavior and its domains, as well as the nutritional behavior score

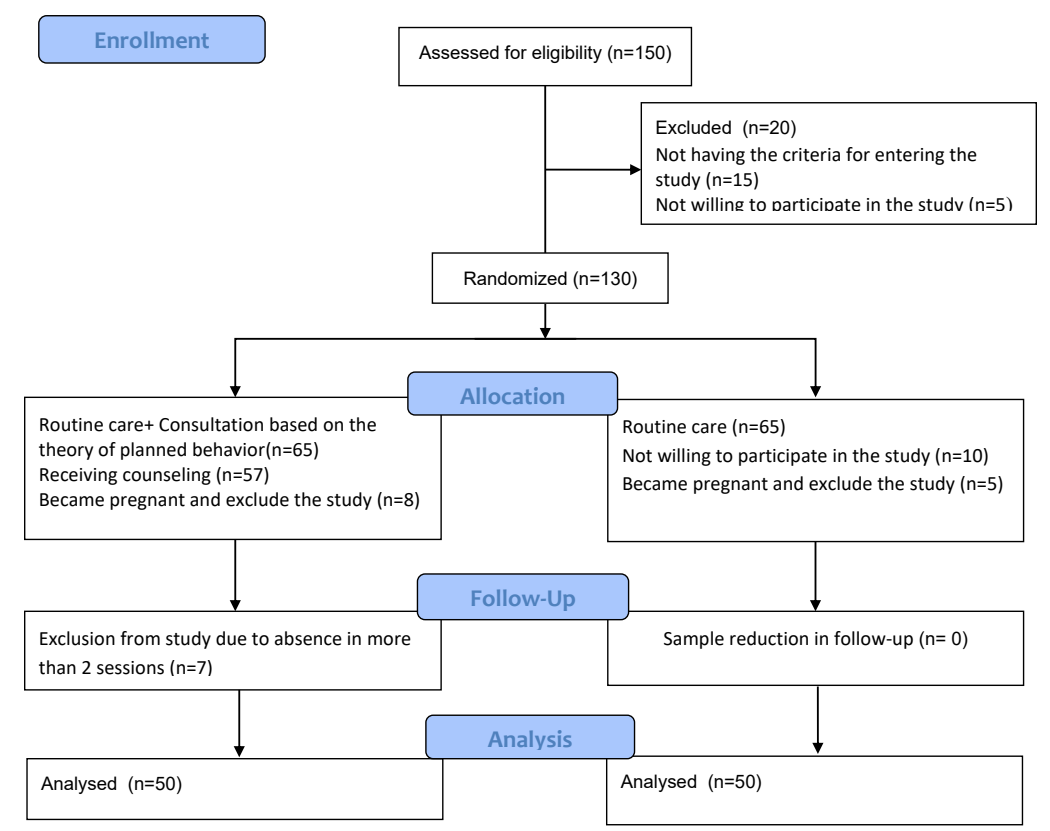

Figure 1. Study Algorithm. 
were assessed after determining the groups and before beginning the study. In the intervention group, five sixtyminute education sessions were held based on the theory of behavioral nutrition behavior weekly in 7 groups with 7 subjects and a group with 8 subjects. The education sessions were followed up by telephone. In addition, the content of the sessions was approved by the faculty members of the Department of Midwifery, Nursing, and Nutrition, along with the Health Education of the Alborz University of Medical Sciences and was as follows:

Session 1: Assessing the needs and emphasizing the importance of dietary changes (the purpose of the study, the complications of obesity and its impact on pregnancy, and the assessment of individual nutritional behavior).

Session 2: Understanding good and bad nutritional behaviors and counseling about the type of eating habit.

Session 3: Creating a positive attitude about a good diet during this session and trying to create a suitable position for women to express their attitudes about changes in nutritional behavior, weight loss, and positive attitudes about an appropriate diet.

Session 4: Addressing participants' behavioral control of compliance with the desired diet (normative and control belief) and identifying the subjective norms of women.

Session 5: Reviewing the suggested diets, appropriate exercise activities, and the presence and expression of the experiences of an overweight woman who succeeded in changing the diet and losing weight.

In this study, the TPB based questionnaire was used, which was designed by Blue and Marrero in the American Society in 2006 (13). The questionnaire was validated by Rohani et al in Iran. It consists of 4 aspects of attitudes toward a healthy diet, subjective norm, perceived behavioral control, and behavioral intention. Cronbach a coefficient for the structures is between 0.99 and 0.9 . In the above-mentioned study, the correlation coefficient for tool reliability was 0.91-0.99 (14).

Further, the validity and reliability of this questionnaire were determined after obtaining permission from the authors and studying the other information sources. Furthermore, quantitative and quantitative content validity of the questionnaire was provided by 10 faculty members of Alborz Medical University, who were experts in reproductive health $(n=5)$, nutrition $(n=3)$, health education $(n=2)$. Moreover, the internal reliability of this questionnaire was determined by 0.84 Cronbach $\alpha$ coefficient and its external reliability was estimated by test re-test. The intraclass correlation coefficient (ICC) for all dimensions was 0.88 . Additionally, the questionnaire was based on a 5-point Likert-type scale ranging from 'Strongly agree $=1$ ' to 'Strongly disagree $=5$ '.

The second questionnaire, designed by Rouhani et al was used to measure nutritional behaviors (14). Then, the content of the questionnaire was quantitatively and qualitatively validated after obtaining permission from the researchers. It should be noted only the last part of this questionnaire was used in the present study, which was related to nutritional behavior. The internal reliability of the questionnaire was determined by the Cronbach $\alpha$ coefficient to 0.87 and for external reliability, a test-retest method was used with an ICC value of 0.905 . The TPB and nutritional behavior scores were analyzed before, after, and 2 months after the intervention. The subjects of the control group received a handbook on the advice given after the end of the study in order to observe the ethics in the research.

\section{Results}

Table 1 represents the demographic characteristics of the contributing subjects in the study. As shown, there was no significant difference between the demographic characteristics in the control and intervention groups.

Mauchly's test indicated that the assumption of sphericity was violated $\left(\chi^{2}=0.382, P=0.000\right)$. Therefore, the degrees of freedom were corrected using the Greenhouse-Geisser estimates of sphericity. The result of the repeated measure test (Table 2) showed that the overall score of the TPB of the 3 times differed significantly $(P=0.002)$, and there was

Table 1. Demographic Characteristics of the Studied Women

\begin{tabular}{|c|c|c|c|}
\hline Variable & Intervention & Control & $P$ Value \\
\hline Age (Mean \pm SD) & $30.4 \pm 5.2$ & $28.7 \pm 5.6$ & $0.128^{\mathrm{a}}$ \\
\hline \multicolumn{4}{|l|}{ Education, No. (\%) } \\
\hline Under the diploma & $1(2)$ & $1(2)$ & \multirow{4}{*}{$0.764^{b}$} \\
\hline Diploma & $19(38)$ & $23(46)$ & \\
\hline University education & $30(60)$ & $27(54)$ & \\
\hline Total & $50(100)$ & $50(100)$ & \\
\hline \multicolumn{4}{|l|}{ Job, No. (\%) } \\
\hline House keeper & $24(50)$ & $31(63.3)$ & \multirow{3}{*}{$0.187^{c}$} \\
\hline Employee & $24(50)$ & $18(36.7)$ & \\
\hline Total & $48(100)$ & 49 (100) & \\
\hline \multicolumn{4}{|c|}{ Income (Toman), No. (\%) } \\
\hline Less than 500000 & $4(8.3)$ & $2(4.2)$ & \multirow{5}{*}{$0.789^{\circ}$} \\
\hline $500000-1000000$ & 11 (22.9) & $14(29.2)$ & \\
\hline $1000000-2000000$ & $22(45.8)$ & $21(43.7)$ & \\
\hline$>2000000$ & $11(22.9)$ & 11 (22.9) & \\
\hline Total & $48(100)$ & $48(100)$ & \\
\hline \multicolumn{4}{|l|}{ No. of children, No. (\%) } \\
\hline 0 & $17(34.7)$ & $23(46)$ & \multirow{6}{*}{$0.688^{c}$} \\
\hline 1 & $14(28.6)$ & $13(26)$ & \\
\hline 2 & $15(30.6)$ & $12(24)$ & \\
\hline 3 & $2(4.1)$ & $2(4)$ & \\
\hline 4 & $1(2.04)$ & 0 & \\
\hline Total & $49(100)$ & $50(100)$ & \\
\hline \multicolumn{4}{|c|}{ Body mass index, No. (\%) } \\
\hline $25-29.5$ & $29(58)$ & $35(70)$ & \multirow{3}{*}{$0.142^{b}$} \\
\hline More than 29.5 & $21(42)$ & $15(30)$ & \\
\hline Total & $50(100)$ & $50(100)$ & \\
\hline
\end{tabular}

${ }^{\mathrm{a}} \boldsymbol{t}$ test; ${ }^{\mathrm{b}}$ Fisher exact test; ${ }^{\mathrm{c}}$ Pearson chi-square test. 
a significant difference between the 2 groups in this regard $(P=0.002)$.

Based on the results of Mauchly's test, the assumption of sphericity was violated $\left(\chi^{2}=0.558, P=0.000\right)$. Thus, the degrees of freedom were corrected by utilizing the Greenhouse-Geisser estimates of sphericity. The result of repeated measure test demonstrated that the nutritional behavior score of the 3 times varied significantly $(P=0.000)$ and a significant difference was found between the 2 groups $(P=0.000)$, the details of which are provided in Table 3.

\section{Discussion}

The results of the study showed that education had a positive effect on the attitude of subjects regarding changing their nutritional behavior $(P=0.002)$. In a study, it was suggested that attitude alone cannot guarantee performance, and according to theories, the behavior is influenced by different factors including controls and norms despite the correlation between attitude and behavior (15). The results of a previous study also confirmed the effect of the TPB educational intervention on the attitude of the nutritional behavior of children and adolescences (16). As regards the dimension of attitude, the most frequent items in the intervention group were "Physical health is good for me" (82\%), "Pregnancy risk reduction is good for me" (96\%), and "Less harm to certain diseases is good for me" (96\%) before, after, and 2 months after the intervention, respectively. Regarding the same dimension in the control group, the highest frequency before, after, and 2 months after the intervention was related to the items of "Physical health is good for me" $(88 \%)$, "Reducing the risks of pregnancy is good for me" $(86 \%)$, "Being less susceptible to certain diseases is fine for me" (86\%), respectively, which reflects the people's attitude toward a healthy diet. In another study respecting overweight women based on the TPB during pregnancy, the highest frequency of attitude to weight gain during pregnancy was related to item "Gaining weight is good for my child" (73\%), and $28 \%$ of women mentioned that overweight is as a cause of physical discomfort (11).

In comparison with before the educational program and the control group, subjective norms of the intervention group represented an increase $(P=0.002)$. These results are consistent with the results of McConnon et al (17) and Kothe et al (18). However, the results of another study (19) showed no significant difference between the mean scores of subjective norms before and after training. In addition, subjective norms had the most predictive power among the other variables of the TPB in a study of the TPB (20). In the present study, the most frequent items respecting the dimension of the subjective norm were "My health care provider encourages me to follow the diet" (54\%) and "I tend to follow the diet and the health care advice" (56\%) in the intervention group before, after, and 2 months after the intervention and the same items had the highest frequency in the following 2 months (62\%). In the control group, the most frequent items concerning the dimension of subjective norms were "My health care provider encourages me to follow the diet" (46\%), and "My relatives agree on changing my diet" (48\%) before, after, and 2 months after the intervention. In a study on the overweight and physical activity of pregnant women, it was shown that the spouse had the most impact on the nutritional behavior and physical activity of mothers during pregnancy and considered $37 \%$ of health care women to be effective in their nutritional behavior (11). According to the results, health care providers had the most impact on changing the nutritional behavior, and the need for more education for these people and their greater emphasis on nutritional behavior was proven as well.

The results of the study further revealed that the scores of behavioral control in those who received an education was higher than those who received no education $(P=0.000)$.

Table 2. The Result of Repeated Measure Test Related to the Theory of Planned Behavior Score Before, After, and 2 Months After the Intervention

\begin{tabular}{|c|c|c|c|c|c|c|c|}
\hline \multirow[t]{2}{*}{ Factor } & \multirow[t]{2}{*}{ Group } & \multirow{2}{*}{$\begin{array}{c}\text { Before } \\
\text { Intervention } \\
\text { Mean } \pm \text { SD }\end{array}$} & \multirow{2}{*}{$\begin{array}{c}\text { After } \\
\text { Intervention } \\
\text { Mean } \pm \text { SD }\end{array}$} & \multirow{2}{*}{$\begin{array}{c}2 \text { Month After } \\
\text { Intervention } \\
\text { Mean } \pm \text { SD }\end{array}$} & \multicolumn{2}{|c|}{$\begin{array}{l}\text { Repeated } \\
\text { Measure }\end{array}$} & \multirow[t]{2}{*}{ Muchly } \\
\hline & & & & & Within Group & Between Group & \\
\hline \multirow{2}{*}{ Attitude } & Intervention & $77.59 \pm 5.66$ & $79.10 \pm 3.6$ & $75.66 \pm 4.99$ & \multirow{2}{*}{$\begin{array}{c}\mathrm{F}=5.39 \\
P=0.007^{\mathrm{a}}\end{array}$} & $F=4.20$ & \multirow{2}{*}{$\begin{aligned} \chi^{2} & =0.874 \\
P & =0.02^{b}\end{aligned}$} \\
\hline & Control & $77.30 \pm 6.4$ & $77.1 \pm 5.3$ & $5.1 \pm 0.77$ & & $P=0.02^{\mathrm{a}}$ & \\
\hline \multirow{2}{*}{ Subjective norm } & Intervention & $43.04 \pm 9.68$ & $45.65 \pm 7.7$ & $38.7 \pm 6.3$ & \multirow{2}{*}{$\begin{array}{l}\mathrm{F}=18.17 \\
P=0.000^{\mathrm{a}}\end{array}$} & \multirow{2}{*}{$\begin{array}{c}\mathrm{F}=8.16 \\
P=0.002^{\mathrm{a}}\end{array}$} & \multirow{2}{*}{$\begin{array}{l}\chi^{2}=0.489 \\
P=0.000^{b}\end{array}$} \\
\hline & Control & $40.9 \pm 5.1$ & $39.6 \pm 9.4$ & $38.28 \pm 9.40$ & & & \\
\hline \multirow{2}{*}{$\begin{array}{l}\text { Perceived } \\
\text { behavioral control }\end{array}$} & Intervention & $35.04 \pm 4.8$ & $36.66 \pm 3.4$ & $37.5 \pm 3.8$ & \multirow{2}{*}{$\begin{array}{l}\mathrm{F}=0.516 \\
P=0.541^{\mathrm{a}}\end{array}$} & \multirow{2}{*}{$\begin{array}{l}\mathrm{F}=15.75 \\
P=0.001^{\mathrm{a}}\end{array}$} & \multirow{2}{*}{$\begin{array}{l}\chi^{2}=0.752 \\
P=0.000^{b}\end{array}$} \\
\hline & Control & $34.64 \pm 6.1$ & $33.85 \pm 5.7$ & $32.7 \pm 5.5$ & & & \\
\hline \multirow{2}{*}{ Intention } & Intervention & $12.68 \pm 2.2$ & $16.86 \pm 1.2$ & $13.84 \pm 1.39$ & \multirow{2}{*}{$\begin{array}{l}\mathrm{F}=20.42 \\
P=0.001^{\mathrm{a}}\end{array}$} & \multirow{2}{*}{$\begin{array}{c}\mathrm{F}=9.92 \\
P=0.001^{\mathrm{a}}\end{array}$} & \multirow{2}{*}{$\begin{array}{l}\chi^{2}=0.958 \\
P=0.128^{c}\end{array}$} \\
\hline & Control & $12.02 \pm 1.9$ & $15.8 \pm 1.9$ & $11.8 \pm 1.8$ & & & \\
\hline \multirow{2}{*}{$\begin{array}{l}\text { Total score of } \\
\text { theory of planned } \\
\text { behavior }\end{array}$} & Intervention & $168.2 \pm 15.1$ & $175.7 \pm 9.8$ & $165.7 \pm 9.6$ & \multirow{2}{*}{$\begin{array}{l}\mathrm{F}=13.74 \\
P=0.001^{\mathrm{a}}\end{array}$} & $F=7.73$ & \multirow{2}{*}{$\begin{array}{l}\chi^{2}=0.382 \\
P=0.000^{b}\end{array}$} \\
\hline & Control & $165.4 \pm 16.6$ & $162.97 \pm 15.9$ & $159.9 \pm 9.08$ & & $P=0.02^{a}$ & \\
\hline
\end{tabular}

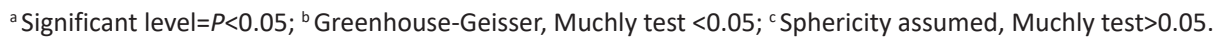


In the intervention group, the most frequent items were "I keep healthy and the recommended foods are available" (44\%), "My family encourage me to eat extra foods until I have a successful pregnancy" (76\%), and "When I eat outdoors, I do not eat healthy food" (84\%) before, after, and 2 months after the intervention. As regards this dimension in the control group, the most frequent items were "I have not enough power to keep healthy and recommended foods available" (46\%), "I agree to some extent that eating healthy foods will make me lose my favorite foods" (44\%), and "I agree that following a healthy diet is expensive" (54\%) before, after, and 2 months after the intervention. Based on the results of another study, most of the nutritional behavior barriers were the guidelines for taking excess calorie recommendations during pregnancy (39\%) and weight loss difficulty (43\%). Moreover, 10\% of women declared social support as a factor to help weightless (11). According to the results, familial and relatives support for the consumption of healthy foods was a controlling factor in nutritional behavior. Accordingly, educating the family members of women with obesity and overweight is essential. In nutritional education studies, the role of perceived behavioral control is emphasized as a predictor of nutritional behavior $(21,22)$. In contrast, Ickes and Sharma found no significant difference in the mean difference between the perceived behavioral control before and after the intervention (21). Similar to the other dimensions of the planned behavior theory, the perceived behavioral control increased in the intervention group after the educational program. In the intervention group, the most frequent items included "I keep healthy and recommended foods" (44\%), "My family encourage me to eat extra foods until I have a successful pregnancy" (76\%), and "When I eat outdoors I do not eat healthy food" $(84 \%)$ in terms of the dimension of behavioral control before, after, and 2 months after the intervention. In the control group, "I have not enough power to keep healthy and recommended foods available" (46\%), "I agree to some extent that eating healthy foods will make me lose my favorite foods" (44\%), and "I agree that following a healthy diet is expensive" (54\%) were the most frequent items before, after, and 2 months after the intervention. Additionally, the scores of behavioral control in those who received training were higher compared to those who received no training $(P=0.000)$. In the study, most of the nutritional behavior barriers were related to the guidelines for taking excess calorie recommendations during pregnancy (39\%) and weight loss difficulty (43\%). In addition, $10 \%$ of women indicated social support as a factor to help lose weight (11).

Based on the results, familial and relatives support in the consumption of healthy foods was a controlling factor in nutritional behavior. Therefore, the education of family members of those women with obesity and overweight is of great importance. In studies related to nutritional education, the role of perceived behavioral control is highlighted as a predictor of nutritional behavior (23). Contrarily, in a study, there was no significant difference in the mean difference between perceived behavioral control before and after the intervention (21).

The results indicated that the score of the individuals' intention increased after education $(P=0.003)$. Regarding the dimension of behavioral intention, the highest frequency belonged to "I plan to follow a healthy diet for the next 3 months" (50\%), "I try to observe a healthy diet before the pregnancy" (86\%), and "the same at the time of delivery" (78\%) before, after, and 2 months after the intervention. In the control group, the prevalence of behavioral intention before, after, and one month after the intervention was the most frequent, which included items such as "I plan to follow a healthy diet in the next 3 months" "I try to keep a healthy diet before I get pregnant" (44\%), "I plan to have a healthy diet in the next 3 months." (62\%), I intend to follow a healthy diet in the next 3 months", and "I try to keep healthy diets before pregnancy" (44\%). The results showed that the intention to behave in the intervention group changed over time $(P=0.000)$.

The findings confirmed the positive impact of counseling on the behavioral intention of subjects and persuaded them to participate even in the following month. A review study revealed that half of the educational interventions that were conducted based on the TPB led to a change in behavioral intention and two-thirds of such interventions caused a behavioral change (24). Based on the findings of another study, behavioral intention alone predicted a $30 \%$ change in behavior while the other dimensions of the TPB could not significantly predict a behavioral change (25). However, the results of another study showed that intention in a group with strong nutritional habits could not predict behavior significantly (26). Similarly, the result of another study failed to show a meaningful relationship between behavioral intent and nutritional behavior in both groups of girls and boys (27).

The results of the current study demonstrated that the total score of the TPB in the intervention group changed over time $(P=0.000)$ and there was a significant difference between the 2 groups in this respect $(P=0.002)$. However, no significant difference was observed in the scores as compared to before and 2 months after education in the intervention group $(P=0.384)$, indicating a lack of continuity of the training and the need for repetition.

The results of this study are in line with those of other studies on the nutritional behavior of adolescent girls (28) and proper breakfast consumption (29). Likewise, some studies showed that TPB can be used effectively in weight loss programs for obese adolescents (30) and their nutritional habits (31).

Hardeman et al reported that although the intention increased after the behavior, the subjective norm represented no change (32). Further, the results of another study showed that only the perceived behavioral control increased as a result of counselling while no change was 
found in the other dimensions of theory (33).

Furthermore, the results indicated that the nutritional behavior in the intervention group changed over time $(P=0.000)$ and a significant difference was detected between the 2 groups $(P=0.000)$. This result is consistent with those of Khodaveisi et al, which showed a change in the mean scores of nutritional behaviors after the intervention in the experimental group of obese and overweight women. Moreover, the healthy nutritional behaviors improved after learning the perceived benefits in the experimental group (34). Similarly, Dunn et al determined the effect of education based on the TPB on fast food eating, as well as preventing and controlling obesity and subsequent illnesses in a long time (35). They found that an increase in the behavioral intention depends on the increase of the 3 dimensions of the theory.

One of the research limitations was the lack of control of the researcher for information sources other than attending the counseling sessions. The researcher advised the subjects not to attend training sessions during the intervention, but other sources of information such as the media and the Internet were uncontrollable.

\section{Conclusions}

Considering the impact of education based on the TPB, it is suggested that the content of this counseling be included in the pre-pregnancy care programs. In addition, trained health care providers should advise the mothers since such people play an essential role in these care programs. Given the lack of continuity of interference during the following 2 months, it is recommended that the program be continuously and repeatedly implemented to achieve the appropriate result. Finally, counseling sessions with family or other relatives is recommended regarding focusing on the role of social support in nutritional behavior.

\section{Conflict of Interests}

The authors declare that there are no conflicts of interest regarding the publication of this article.

\section{Ethical Issues}

The present study was performed with the permission of the Vice-chancellor for the Research of Alborz University of Medical Sciences. In addition, it was registered in the Iranian Registry of Clinical Trials (identifier: IRCT2015011920719N1; https://en.irct.ir/trial/18316) after obtaining ethical approval from the Research Ethics Committee of Alborz University (Abzums.Rec.1395.151). Further, all the subjects signed informed consent and were assured of the confidentiality of all their personal information. The researchers attempted to observe all the participants' rights.

\section{Financial Support}

Alborz University of Medical Sciences supported this study.

\section{Acknowledgments}

The authors would like to thank the Clinical Research Development Center of Kamali hospital for spiritual and financial support.

\section{References}

1. Hackman CL, Knowlden AP. Theory of reasoned action and theory of planned behavior-based dietary interventions in adolescents and young adults: a systematic review. Adolesc Health Med Ther. 2014;5:101-114. doi:10.2147/ ahmt.s56207

2. Stüber TN, Künzel EC, Zollner U, Rehn M, Wöckel A, Hönig A. Prevalence and Associated Risk Factors for Obesity During Pregnancy Over Time. Geburtshilfe Frauenheilkd. 2015;75(9):923-928. doi:10.1055/s-0035-1557868

3. Tanvig M. Offspring body size and metabolic profile effects of lifestyle intervention in obese pregnant women. Dan Med J. 2014;61(7):B4893.

4. Endocrinology and Metabolism Research Institute. obesity and its complications. http://emri.tums.ac.ir.

5. Guilloty NI, Soto R, Anzalota L, Rosario Z, Cordero JF, Palacios C. Diet, Pre-pregnancy BMI, and Gestational Weight Gain in Puerto Rican Women. Matern Child Health J. 2015;19(11):2453-2461. doi:10.1007/s10995-015-1764-4

6. Barrett G, Shawe J, Howden B, et al. Why do women invest in pre-pregnancy health and care? A qualitative investigation with women attending maternity services. BMC Pregnancy Childbirth. 2015;15:236. doi:10.1186/s12884-015-0672-3

7. Shin D, Lee KW, Song WO. Pre-Pregnancy Weight Status Is Associated with Diet Quality and Nutritional Biomarkers during Pregnancy. Nutrients. 2016;8(3):162. doi:10.3390/ nu8030162

8. ACOG Committee Opinion number 313, September 2005. The importance of preconception care in the continuum of women's health care. Obstet Gynecol. 2005;106(3):665-666. doi:10.1097/00006250-200509000-00052

9. Lash DN, Smith JE, Rinehart JK. Can the Theory of Planned Behavior predict dietary intention and future dieting in an ethnically diverse sample of overweight and obese veterans attending medical clinics? Appetite. 2016;99:185-192. doi:10.1016/j.appet.2016.01.013

10. de Bruijn GJ, Kroeze W, Oenema A, Brug J. Saturated fat consumption and the Theory of Planned Behaviour: exploring additive and interactive effects of habit strength. Appetite. 2008;51(2):318-323. doi:10.1016/j. appet.2008.03.012

11. Whitaker KM, Wilcox S, Liu J, Blair SN, Pate RR. Pregnant women's perceptions of weight gain, physical activity, and nutrition using Theory of Planned Behavior constructs. J Behav Med. 2016;39(1):41-54. doi:10.1007/s10865-0159672-z

12. Bahadori-Monfared A, Keramati AA, Moazami-Sahzabi J, Mohamadi F, Farsar AR. The impact of education on nutritional behavior change among clients of Sardar-Jangal health center in 2012. Community Health. 2014;1(1):62-68. [Persian].

13. Blue CL, Marrero DG. Psychometric properties of the healthful eating belief scales for persons at risk of diabetes. J Nutr Educ Behav. 2006;38(3):134-142. doi:10.1016/j. jneb.2006.01.010 
14. Rohani H, Eslami A, Raei M, Tavakoli Ghouchani H, Afshari A. Psychometric properties of the healthful eating belief scales for type 2 diabetics. Journal of North Khorasan University of Medical Sciences. 2014;6(2):319-327. doi:10.29252/jnkums.6.2.319

15. Kim E, Ham S, Yang IS, Choi JG. The roles of attitude, subjective norm, and perceived behavioral control in the formation of consumers' behavioral intentions to read menu labels in the restaurant industry. Int J Hosp Manag. 2013;35:203-213. doi:10.1016/j.ijhm.2013.06.008

16. Riebl SK, Estabrooks PA, Dunsmore JC, et al. A systematic literature review and meta-analysis: The Theory of Planned Behavior's application to understand and predict nutritionrelated behaviors in youth. Eat Behav. 2015;18:160-178. doi:10.1016/j.eatbeh.2015.05.016

17. McConnon A, Raats M, Astrup A, et al. Application of the Theory of Planned Behaviour to weight control in an overweight cohort. Results from a pan-European dietary intervention trial (DiOGenes). Appetite. 2012;58(1):313318. doi:10.1016/j.appet.2011.10.017

18. Kothe EJ, Mullan BA, Butow P. Promoting fruit and vegetable consumption. Testing an intervention based on the theory of planned behaviour. Appetite. 2012;58(3):9971004. doi:10.1016/j.appet.2012.02.012

19. Schifter DE, Ajzen I. Intention, perceived control, and weight loss: an application of the theory of planned behavior. J Pers Soc Psychol. 1985;49(3):843-851. doi:10.1037//00223514.49.3.843

20. Pawlak R, Connell C, Brown D, Meyer MK, Yadrick K. Predictors of multivitamin supplement use among AfricanAmerican female students: a prospective study utilizing the theory of planned behavior. Ethn Dis. 2005;15(4):540-547.

21. Ickes MJ, Sharma M. Does behavioral intention predict nutrition behaviors related to adolescent obesity? Infant Child Adolesc Nutr. 2011;3(1):38-48. doi:10.1177/1941406410395017

22. Poston L, Briley AL, Barr S, et al. Developing a complex intervention for diet and activity behaviour change in obese pregnant women (the UPBEAT trial); assessment of behavioural change and process evaluation in a pilot randomised controlled trial. BMC Pregnancy Childbirth. 2013;13:148. doi:10.1186/1471-2393-13-148

23. Whitaker KM, Wilcox S, Liu J, Blair SN, Pate RR. Pregnant women's perceptions of weight gain, physical activity, and nutrition using Theory of Planned Behavior constructs. J Behav Med. 2016;39(1):41-54. doi:10.1007/s10865-0159672-Z

24. Hardeman W, Johnston M, Johnston D, Bonetti D, Wareham N, Kinmonth AL. Application of the theory of planned behaviour in behaviour change interventions: A systematic review. Psychol Health. 2002;17(2):123-158. doi:10.1080/08870440290013644a

25. Kothe EJ, Mullan BA, Butow P. Promoting fruit and vegetable consumption. Testing an intervention based on the theory of planned behaviour. Appetite. 2012;58(3):9971004. doi:10.1016/j.appet.2012.02.012

26. de Bruijn GJ. Understanding college students' fruit consumption. Integrating habit strength in the theory of planned behaviour. Appetite. 2010;54(1):16-22. doi:10.1016/j.appet.2009.08.007

27. Fila SA, Smith C. Applying the Theory of Planned Behavior to healthy eating behaviors in urban Native American youth. Int J Behav Nutr Phys Act. 2006;3:11. doi:10.1186/14795868-3-11

28. Pooreh S, Hosseini Nodeh Z. Impact of Education Based on Theory of Planned Behavior: An Investigation into Hypertension-Preventive Self-care Behaviors in Iranian Girl Adolescent. Iran J Public Health. 2015;44(6):839-847.

29. KotheEJ, Mullan BA, Amaratunga R. Randomised controlled trial of a brief theory-based intervention promoting breakfast consumption. Appetite. 2011;56(1):148-155. doi:10.1016/j.appet.2010.12.002

30. Mazloomy-Mahmoodabad SS, Navabi ZS, Ahmadi A, Askarishahi M. The effect of educational intervention on weight loss in adolescents with overweight and obesity: Application of the theory of planned behavior. ARYA Atheroscler. 2017;13(4):176-183.

31. Riebl SK, Estabrooks PA, Dunsmore JC, et al. A systematic literature review and meta-analysis: The Theory of Planned Behavior's application to understand and predict nutritionrelated behaviors in youth. Eat Behav. 2015;18:160-178. doi:10.1016/j.eatbeh.2015.05.016

32. Hardeman W, Kinmonth AL, Michie S, Sutton S. Impact of a physical activity intervention program on cognitive predictors of behaviour among adults at risk of Type 2 diabetes (ProActive randomised controlled trial). Int J Behav Nutr Phys Act. 2009;6:16. doi:10.1186/1479-58686-16

33. Parrott MW, Tennant LK, Olejnik S, Poudevigne MS. Theory of Planned Behavior: Implications for an emailbased physical activity intervention. Psychology of Sport and Exercise. 2008;9(4):511-526. doi:10.1016/j. psychsport.2007.07.002

34. Khodaveisi MP, Omidi AM, Farokhi SM, Soltanian ARP. The Effect of Pender's Health Promotion Model in Improving the Nutritional Behavior of Overweight and Obese Women. Int J Community Based Nurs Midwifery. 2017;5(2):165-174.

35. Dunn KI, Mohr P, Wilson CJ, Wittert GA. Determinants of fast-food consumption. An application of the Theory of Planned Behaviour. Appetite. 2011;57(2):349-357. doi:10.1016/j.appet.2011.06.004

(C) 2019 The Author (s); This is an open-access article distributed under the terms of the Creative Commons Attribution License (http://creativecommons.org/licenses/by/4.0), which permits unrestricted use, distribution, and reproduction in any medium, provided the original work is properly cited. 